\title{
PARALOGISMOS. UNA CONTRIBUCIÓN DE C. VAZ FERREIRA AL ANÁLISIS DE LA ARGUMENTACIÓN FALAZ*
}

\author{
Luis Vega Reñón **
}

UNED

RESUMEN: En recuerdo del 50.a aniversario de C. VAZ FERREIRA (†1958/2008), me propongo, primero, mostrar la singularidad de su idea del paralogismo dentro de la tradición de las falacias, debida no sólo a su peculiar marco "psico-lógico» de planteamiento, sino a su concepción del paralogismo como un proceso o estado de confusión y una fuente de errores mentales y cognitivos antes que discursivos; y segundo, trasladar esta idea al campo actual de la argumentación para aprovechar su poder de sugerencia. Pues la contribución de VAZ FerReIRA no se limita a la lúcida exploración e ilustración del paralogismo como una dimensión del discurrir falaz, antes de él apenas entrevista, sino que además abunda en sugerencias dignas de tenerse en cuenta en la discusión actual en torno a la argumentación falaz.

Palabras clave: C. VAZ FERREIRA, falacias, paralogismo, errores mentales y cognitivos, argumentación.

ABSTRACT: In memory of the $50^{\text {th }}$ anniversary of C. VAZ FERREIRA ( $\left.+1958 / 2008\right)$, I intend (1) to show the singularity of his idea of paralogism inside the fallacy tradition, due not only to his «psychologic" frame of approach, but to his conception of the paralogism as a process or state of confusion and a source of mistakes rather mental and cognitive than discursive; and (2) to translate this idea to the present-day field of argumentation to take here advantage of its power of suggestion. VAZ's contribution is not confined itself to the lucid exploration and illustration of the paralogism as a dimension of fallacious reasoning barely glimpsed before him, but it also abounds with hints worth being born in mind in our current discussions about fallacious argumentation.

Keywords: C. VAZ FERREIRA, fallacies, paralogism, mental and cognitive mistakes, argumentation.

* Fecha de recepción: 28 de junio de 2008. Fecha de aceptación: 31 de julio de 2008.

** Trabajo realizado en el marco del proyecto HUM2005-00365, financiado por el MEC. 


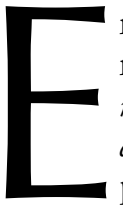

n 2008 celebramos el 50. aniversario de la publicación de dos obras fundacionales de la teoría actual de la argumentación: Traité de l'Argumentation. La nouvelle rhétorique de Ch. Perelman y L. OlBReChTS-TyteCA, y The uses of argument de S. Toulmin ${ }^{1}$. Por una - digamos- «ironía de la historia», a principios de ese mismo año en que nacía la teoría de la argumentación, 1958, moría en Montevideo C. VAZ FERREIRA, uno de los padres de la filosofía latinoamericana contemporánea y seguramente el más lúcido analista de la argumentación falaz que hemos tenido en nuestra lengua y cultura hispanas. Puede que VAZ, a sus 85 años, muriera demasiado pronto y que nuestra teoría de la argumentación naciera demasiado tarde. Lo cierto es que no se encontraron y esto ha sido una pena por ambas partes: todavía hoy, la fina concepción del paralogismo que había avanzado VAZ en los años 1908-1910, en especial en (1910) Lógica viva, anda sin papeles por el mundo de las falacias, y no cabe dar con su nombre en las referencias y bibliografías al uso en Lógica informal, Teoría de la argumentación o Pensamiento crítico. De modo que a nadie le extrañará que aproveche el presente cincuentenario de la muerte de VAZ no sólo para hacer públicos sus méritos, sino para mostrar el poder de sugerencia de sus ideas — «larvas de ideas», según dijera de ellas UNAMUNO— sobre los paralogismos, y para resaltar esta dimensión del discurso falaz tradicionalmente oculta o preterida incluso en los manuales más al día —e. g. DAMER, 2005, y TiNDALE, 2007.

\section{FALACIAS, SOFISMAS Y PARALOGISMOS}

La contribución más relevante de la Lógica viva es el estudio del paralogismo y el aporte más original es su concepción como un proceso o estado de confusión y una fuente de errores mentales y cognitivos antes que discursivos. Los paralogismos se han considerado tradicionalmente una especie del género de las falacias. Pero aquí no nos van a interesar como clases o tipos de discurso, pues no vamos a examinar catálogos o repertorios de falacias. Hoy día las falacias en general y los paralogismos en particular merecen atención no sólo o no tanto por sus servicios escolares, a efectos clasificatorios críticos o didácticos, como por su condición refleja y su significación sintomática, es decir: por su calidad de espejo de ciertas cuestiones y perspectivas básicas con que nos encontramos en la teoría actual de la argumentación. Pues bien, ¿qué puede indicarnos o sugerirnos la Lógica viva de VAZ FERREIRA a este respecto?

Antes de nada, recordemos las pretensiones que guían este libro: lo que ofrece son observaciones e ideas a tener en cuenta, pero no claves doctrinales de una teoría o de un sistema. Esta distinción entre «pensar por sistemas» $\mathrm{y}$ «pensar por ideas para tener en cuenta» es justamente una de las puntualizaciones que introduce la Lógica viva: al pensar por sistemas consideramos algo destinado a aplicarse o cumplirse en todos los casos; al pensar por ideas observamos o anotamos algo que conviene tomar en consideración cuando abordamos un caso o reflexionamos sobre el particular. Podemos emplear el primer procedimiento, recurrir a sistemas, si disponemos de todos los principios y hechos pertinentes sobre el asunto tratado, si los principios y los datos se dejan

${ }^{1}$ De las dos hay versión castellana: 1989: Tratado de la argumentación: la nueva retórica, Madrid: Gredos, y 2007: Los usos de la argumentación, Barcelona: Península. 
integrar en un razonamiento general y si los casos estudiados son iguales u homogéneos, como ocurriría según VAZ en determinados marcos metodológicos, e. g. los propios de las matemáticas o de la mecánica. El otro es, en cambio, el procedimiento indicado cuando hemos de tratar con cuestiones de grado y de matiz, y con muestras concretas, dispares y particulares como los paralogismos de que vamos a ocuparnos. En nuestros días, la inadecuación de pensar por teorías generales o sistemas cerrados en este terreno parece aún más notoria que en tiempos de VAZ FERREIRA: desde 1970 cunde la impresión de que no hay ni ha habido una teoría general de las falacias e incluso algunos dudan de que pueda haberla. Sea como fuere, aquí seguiré el proceder de VAZ FERREIRA de hacer observaciones y apuntar sugerencias, sin ninguna pretensión de cerrar el tema sino, al contrario, con la intención de abrir nuevos frentes.

Partamos, para entendernos, de una noción genérica de falacia y de una visión comprensiva del campo tradicional de los sofismas y los paralogismos.

\section{1}

En nuestros usos comunes, falacia y falaz se dicen de acciones o cosas censurables que suelen envolver falsedad o engaño. Convengamos en aplicar estos términos a actividades lingüísticas o discursivas que tienen lugar en el contexto de una argumentación o con un propósito argumentativo ${ }^{2}$. También cabe recordar dos líneas de sentido del étimo latino de los términos castellanos, el verbo «fallo». «Fallere» significa: 1 Engañar o inducir a error. 2 Fallar, incumplir, defraudar. Seguiré esta pauta y consideraré falaz, en principio, el discurso que se presta o induce a error en un contexto argumentativo por ser falso, fallido o fraudulento. En términos más precisos: considero falaz la acción discursiva que pasa o se quiere hacer pasar por una buena argumentación —o al menos por mejor de lo que es-, y en esa medida se presta o induce a error pues en realidad se trata de un seudo argumento o de una argumentación fallida o fraudulenta.

También se ha hablado desde antiguo de «sofismas» y de «paralogismos»: un sofisma es un ardid deliberado o una argucia dolosa, mientras que un paralogismo es más bien un error involuntario, un fallo o un descuido. Los sofismas se cometen a sabiendas. En los paralogismos se incurre inadvertidamente. Ambos casos vienen comprendidos en la noción anterior: la falacia que pasa por lo que no es y en esa medida se presta a error sería un paralogismo, mientras que la falacia que queremos hacer pasar por lo que no es y en esa medida induce a engaño sería un sofisma. Esta distinción ya consta expresamente, por ejemplo, en el tratado De fallaciis (siglo XIII) atribuido a T. DE AQUINO, aunque no deje de haber atisbos e indicaciones anteriores.

${ }^{2}$ La imputación de «falaz» o de «falacia» puede aplicarse a diversos actos o productos discursivos como proposiciones (e.g. «el tópico de que los españoles son ingobernables es una falacia»), preguntas (e.g. «la interpelación capciosa "¿Ha dejado Ud. de robar?" es una conocida falacia») o argumentos (e.g. «no vale oponer a quien se declara en favor del suicidio un argumento falaz del tenor de "Si defiendes el suicidio, deberías tirarte por la ventana"». Supondré que los términos «falaz» o «falacia» se aplican primordialmente a discursos que son o pretenden ser argumentos. Por derivación, cabe considerar falaces otras unidades discursivas (proposiciones, preguntas, etc.) en la medida en que forman parte sustancial de una argumentación o contribuyen a unos propósitos argumentativos. Este contexto argumentativo - entre otros factores como el marco normativo de evaluación y el carácter censurable - también ayudaría a distinguir los casos falaces de otros fallos o errores como las ilusiones cognitivas en general (cfr. POHL, 2004). 
Puestas así las cosas, propongo contemplar el campo de la argumentación como un terreno donde medran tanto las buenas como las malas hierbas. Entre las malas hierbas figuran las múltiples variedades de la argumentación falaz que cubren desde el yerro más ingenuo debido a incompetencia o a inadvertencia, en el extremo de los paralogismos, hasta el engaño urdido subrepticia y deliberadamente en el extremo opuesto de los sofismas. Hay, por cierto, variantes que se solapan o se muestran a veces graduales e indecisas, hasta el punto de que el espectro de la argumentación falaz parece extenderse como una especie de continuo. Pero estos grados y matices intermedios no borran la distinción y distancia entre ambos extremos, al igual que una gama de colores grises no difumina la diferencia entre el blanco y el negro.

\section{2}

Según otra presunción habitual de la tradición lógica, las falacias más relevantes son las que tienden al polo de los sofismas efectivos y con éxito, es decir las estrategias capciosas que logran confundir o engañar al receptor del discurso, sea un interlocutor, un jurado, un auditorio, el público. Por ejemplo, durante la pasada legislatura se adujo el siguiente dilema contra la política de entablar conversaciones con ETA: en el curso de las conversaciones, o el Gobierno pacta con ETA o no pacta con ETA; si pacta, se rendirá a sus exigencias y traicionará la sangre de las víctimas; si no pacta, se expondrá a nuevos atentados y más violencia. He ahí un sofisma. El estudio de los sofismas en el campo de la argumentación responde, entre otros servicios, a su penetración crítica. Gracias a esa idea de sofisma, podemos detectar no sólo el recurso a argumentos espurios como el dilema citado, sino la manipulación falaz de formas correctas de razonamiento - de modo análogo a como podemos reconocer el discurso que trata de engañar con la verdad ${ }^{3}$ - Dando un paso más, podemos advertir no sólo sus efectos perversos sobre la inducción de creencias o disposiciones, sino su contribución a minar la confianza básica en los usos del discurso. De hecho, el dilema anterior formaba parte de una estrategia de crispación que amenazó con pervertir - y a veces pervirtió- el discurso político. Pero su importancia también estriba en lo que unos sofismas cumplidos nos revelan acerca de la argumentación en general. En tales casos, la argumentación falaz se desenvuelve en un marco no sólo discursivo sino interactivo: para que alguien engañe, alguien tiene que ser engañado. La dualidad de sofismas y paralogismos presenta así una correlación de ambos: el éxito de un sofisma cometido por un emisor trae aparejada la comisión de un paralogismo por parte de un receptor, de modo que la complicidad del receptor es co-determinante de la suerte del argumento.

Por su parte, la consideración de los casos o estados paralogísticos también tiene una significación especial: si la importancia de los sofismas nos remite a la dimensión

\footnotetext{
${ }^{3}$ Recordemos, de paso, la fortuna del tópico de «engañar con la verdad» en las comedias de enredo, véase J. Roso, 2002: «Engañar a la manera de Lope. Apuntes sobre el recurso en la dramaturgia barrica», Anuario de Estudios Filológicos, 25, 445-460. «Engañar con la verdad» es, por otra parte, el título de una versión española —a cargo de BRETÓN DE LOS HERREROS— de Les fauses confidences (1738) de Marivaux. Por lo demás, el propio Aristóteles ya había advertido la existencia de usos falaces — por inadecuación al marco temático o metodológico involucrado- de silogismos válidos (e. g. en Refutaciones sofísticas, 169b21-23).
} 
dialéctica y retórica de la argumentación —e. g. a la interacción y la inducción-, la de los paralogismos estriba en su dimensión epistémica o, más en general, cognitiva, y en sus relaciones con la idea de error lógico y con ciertas ilusiones «inferenciales» $\mathrm{o}$ «discursivas». Veamos una muestra de las que en psicología se han llamado «inferencias ilusorias» (JOHNSON-LAIRD y SAVARY, 1999):

Consideremos las siguientes aserciones referidas a una determinada mano de cartas (grupo de cartas repartido a cada jugador de un juego de baraja):

i) «Si en esta mano hay un rey, entonces hay un as o, en caso contrario, si hay una reina, entonces hay un as en esta misma mano».

ii) «Hay un rey en esta mano».

¿Qué se sigue lógicamente de i) y ii)?

La respuesta habitual en las pruebas con este test es que se sigue que hay un as. Bien sea por Modus Ponens a partir de la primera disyuntiva y ii), o bien, en todo caso, porque las dos condiciones pertinentes son la presencia de un rey o de una reina, y según i) tanto una como otra carta estaría acompañada por un as.

Es una respuesta errónea aunque nos parezca «natural». Se trata de una ilusión inferencial, según cabe mostrar a la luz del uso lógico del condicional: un condicional es falso si su prótasis es verdadera y su apódosis falsa; es verdadero en cualquier otro caso.

La aserción i) puede ser verdadera tanto en la condición rey $\rightarrow$ as, como alternativamente en la condición reina $\rightarrow$ as. En otras palabras, la disyunción es compatible con la falsedad de una de las dos condicionales que la componen. Así pues, el primer condicional puede ser falso. En este caso, por definición, dada la prótasis: «hay un rey», no se daría la apódosis: «hay un as»; y Modus Ponens tampoco sería aplicable. Por lo demás, nada asegura la presencia de una reina en la otra alternativa, ni la de un as: pues el condicional puede ser verdadero siendo sus dos miembros falsos. Por consiguiente, de i) y ii) no se sigue que haya un as en la mano.

El condicional es un operador lógico delicado que suele prestarse a errores o fa$l \operatorname{los}^{4}$, así como los cuantificadores o los operadores modales cuando se hallan incrustados. Pero VAz FerReIra discurría al margen de este tipo específico de fallos o dificultades que ponen en cuestión nuestra competencia lógica estándar, sean ilusiones inferenciales semejantes a las ilusiones ópticas, o sean paralogismos propiamente dichos, i. e. cometidos en un contexto o con un propósito argumentativos. Le importaban otros casos más comunes y ordinarios y, en este sentido, hay que reconocer que tanto la diagnosis como el estudio de ciertas modalidades y efectos deletéreos de los paralogismos usuales son méritos distintivos de su Lógica viva. Su significación no se deriva sólo de la frecuencia y de la «naturalidad» de los propios paralogismos, ni se debe solamente a las lúcidas observaciones de VAZ sobre algunas variedades típicas, como la falsa oposición, la falsa precisión, el trato erróneo de las cuestiones normativas como si fueran explicativas, o las trampas subyacentes en la sistematización del pensamiento o en el esquematismo del lenguaje. Su significación también estriba en la pro-

${ }^{4}$ De ahí que en las pruebas de razonamiento lógico para los candidatos a las facultades de Derecho en EEUU y Canadá, LSAT (Law School Admission Tests) abunden los casos de condicionales; véase e. g. D. M. KILLORAN, 2007: LSAT Logical Reasoning Bible, Milton Head Island (Canada): PowerScore. 
yección del planteamiento «psico-lógico» de VAZ sobre ciertos aspectos de nuestras prácticas argumentativas a veces descuidados, como los cognitivos por ejemplo. Así pues, para apreciar esa significación como es debido, deberemos partir de una visión más general de las ideas de VAZ FERREIRA sobre la lógica y las falacias.

\section{UNA APORTACIÓN TÁCTICA Y DOS SUPUESTOS ESTRATÉGICOS}

Resumiré el legado de VAZ FERREIRA a este respecto en tres puntos principales: un giro digamos táctico y dos supuestos estratégicos. El giro táctico tiene que ver con su tratamiento de los casos considerados: consiste en abandonar la vía tradicional de los tipos y las clases de falacias para fijarse en los usos y las disposiciones falaces que presentan multitud de ejemplos tomados de la práctica común y cotidiana en diversos géneros de discurso público (e.g. periodístico, parlamentario, académico). Así pues, frente a la consideración lógica abstracta de cómo uno podría o debería equivocarse, la Lógica viva pasa a considerar cómo, efectivamente, la gente se equivoca y cómo se muestra de ordinario predispuesta a hacerlo. Ahora bien, este cambio táctico del foco de atención, este giro desde las falacias de catálogo hasta nuestras prácticas falaces, responde a ciertos supuestos estratégicos más innovadores y profundos.

Dos de estos supuestos merecen a mi juicio especial atención.

Uno guarda relación con la idea básica de paralogismo. Se funda en la revisión del análisis desarrollado por la Lógica de J. STUART MILL ${ }^{5}$ de una nueva clase de falacias —que J. BENTHAM había avanzado en otro sentido-: las falacias de confusión o errores discursivos cometidos por un pensamiento confuso e indistinto como el que incurre inadvertidamente en ambigüedad, petición de principio o ignorancia de la cuestión; fallos casi insensibles que, una vez advertidos, pueden parecer sorprendentes en una mente despierta. Pero VAz hace notar - y este un punto de perspicacia y originalidad - que no constituyen en realidad una clase determinada de falacias, sino un modo de caer en ellas, sea cual sea su clase. Dice: «habrá diversos modos psicológicos de caer en las falacias: sin razonar o casi sin razonar...; razonando muy confusamente, menos confusamente, y así por grados hasta el caso en verdad menos común del mal raciocinio distintamente concebido» (Un paralogismo de actualidad, 1908, en VAZ, 1979: p. 177). Por lo demás, su comisión no sólo revelaría incompetencia, poca inteligencia o falta de instrucción, pues tales paralogismos también pueden darse de forma incipiente, indecisa o aun prediscursiva en mentes preparadas (ibídem). Estas observaciones llevan a reconocer diversos modos de incurrir en usos -o de hallarse en estados-paralogísticos, en particular: $a$ ) un modo explícitamente discursivo; $b$ ) un modo confuso pero explicitable; $c$ ) un modo confuso e irreducible al discurso expreso o, al decir de VAZ, «sub-discursivo», que según él sería por cierto el más común y característico ${ }^{6}$.

El segundo supuesto, de carácter más general, responde a una profunda convicción formulable en estos términos: «lo que expresamos es una mínima parte de lo que

\footnotetext{
5 Véase MiLl, 1917: libro V, cap. II, \$2, pp. 730-31, y cap. VII, pp. 806-831.

${ }^{6}$ Véase Palladino, 1962: en especial pp. 170, 173.
} 
pensamos y lo que pensamos es una mínima parte de lo que psiqueamos "es decir, de lo que vivimos intelectual, sensitiva y afectivamente" ${ }^{7}$. De este supuesto se desprende un par de ideas básicas de la «Psico-Lógica» de VAZ: por un lado, i) ni los esquemas verbales, ni menos aún los patrones lógicos, pueden imponerse y ahormar los procesos psicológicos; por otro lado, ii) hay una lógica pre- o sub-discursiva ignorada o desatendida por la lógica tradicional. Ambas ideas se oponen a la pretensión clásica del análisis lógico de atenerse estrictamente al razonamiento expreso (VAZ, 1945: p. 190) y a la concepción tradicional de los sofismas como falacias clara y distintamente concebidas (VAZ, 1979: pp. 176-177). Frente a esta idea canónica y precisa del sofisma, los paralogismos que a VAZ FERREIRA le importa detectar y examinar vienen a ser unos procesos «psíquico-lógicos» por los que caemos o nos encontramos en estados de neblina que tiñen, velan o enturbian nuestra mente, «nos impiden ver y pensar con justeza» (1945: p. 135) ${ }^{8}$.

Valga como ejemplo el paralogismo de la falsa oposición. Según VAZ: «Es una de las falacias más comunes, y por la cual se gasta en pura pérdida la mayor parte del trabajo pensante de la humanidad, la que consiste en tomar por contradictorio lo que no es contradictorio; en crear falsos dilemas, falsas oposiciones. Dentro de esta falacia, la muy común que consiste en tomar lo complementario por contradictorio no es más que un caso particular de ella, pero un caso prácticamente muy importante» (1945: p. 11, cursivas en el original). Por otra parte, este paralogismo puede presentarse bajo formas no solo burdas y evidentes, sino celadas y sutiles. Así, tras ofrecer unas primeras muestras flagrantes de disyuntivas forzadas o indebidamente excluyentes, VAz hace notar: «Ahora, debo advertirles que, en la mayoría de los casos prácticos, nuestro paralogismo no se ve tan claramente. En la realidad, lo que hace la falacia de falsa oposición es, sobre todo, confundir más o menos, como sombrear las cuestiones» (1945: p. 18). Nos encontramos, en definitiva, ante un paralogismo de confusión típico.

En la Lógica viva, la falsa oposición presenta tres variedades principales: 1) una muy genérica consiste en tomar por opuestos contradictorios dos extremos que son más bien contrarios o simplemente dispares pero no irreconciliables; las otras dos, más específicas, son 2) el falso dilema que juzga excluyentes entre sí unos casos complementarios, y 3) el descarte empeñado en tratar como incompatibles los factores o elementos concurrentes en un caso complejo (VAZ, en otros momentos y lugares, también se ocupará de otros paralogismos relacionados con la contradicción y de otros casos distintos de contraposición, por ejemplo, entre ideales que llama «interferentes», i. e. fines que interfieren entre sí o valores en conflicto irreducible).

La modalidad primera (1) no parece atraer especialmente la atención de la Lógica viva, aunque la historia de la filosofía viene cargada de ejemplos a partir del paradigma de falsa oposición que representan los primeros versos de la revelación de la diosa en el Poema de Parménides. Recordemos que, a juicio de Parménides o a tenor de lo que

\footnotetext{
${ }^{7}$ Cfr. el prólogo de M. CLAPS a la edición de VAZ, 1979: p. xxii.

${ }^{8}$ En ocasiones, VAZ lamenta verse obligado a esta suerte de expresiones metafóricas para dar cuenta de los fenómenos confusos e innominados aludidos: «Me desespera tener que usar estas metáforas ("teñir", "velar", "enturbiar", etc.): el lector querrá interpretarlas de acuerdo con la buena psicología» (1979: p. 177). Cfr. también una acotación en análogo sentido a propósito de lo que, en otro contexto, denomina «instinto lógico» o «buen sentido hiperlógico» (1945: p. 194, n. 1).
} 
la diosa declara, sólo cabe concebir dos caminos de investigación acerca del ser: i) que es y no es posible que no sea, i. e. la vía de la verdad bien redonda, y ii) que no es y es necesario que no sea, i. e. la vía de lo absolutamente incognoscible e inescrutable (28 B 2, 3-5). Luego, en conclusión, no queda sino un único camino pensable o practicable, que es y no es posible no ser (28 B 81 1-2). Pero ni que decir tiene que, entre los dos extremos contrapuestos, caben efectivamente otros casos no considerados, como el de que no es necesario que sea y el de que no es necesario que no sea; casos que abren, en suma, la vía de la contingencia frente a las dos vías anteriores de la necesidad de ser y la necesidad de no ser. Así pues, lejos de ser contradictorios los extremos iniciales de lo que es y lo que no es, no pasan de resultar — dentro de su imprecisión - contrarios y, en definitiva, no llegan a determinar esa suerte de silogismo disyuntivo que el Poema pretende: no establecen la disyunción excluyente sobre la que Parménides quiere sentar, dada la imposibilidad e inaceptabilidad absoluta del no ser, la imperiosa necesidad del ser' ${ }^{9}$. De ser cierta la significación fundacional que suele reconocerse al Poema de Parménides, cabría pensar que el primer paso histórico de la filosofía es un tropiezo en un paralogismo.

Frente a la ausencia de muestras y análisis de paralogismos de este tipo, debida quizás a su carácter más escolar y abstracto, VAZ prodiga detalles y ejemplos a propósito de las otras dos modalidades específicas. Una buena muestra de los paralogismos excluyentes de tipo (2) podría ser la generada en torno a una propuesta que avanzara él mismo en el Consejo Universitario: VAZ proponía hacer obligatoria durante el Bachillerato la lectura de obras originales, prestadas por la Universidad, para familiarizar a los estudiantes con los grandes autores y elevar el nivel de enseñanza. La propuesta suscitó una discusión entre los colegas que compartían ambos objetivos pero discrepaban de los medios y medidas al respecto: uno alegaba que el verdadero procedimiento para ese fin era organizar conferencias; otro se oponía señalando que el procedimiento indicado consistía en que fueran los profesores quienes hicieran las lecturas en clase. «Y así continuaron varios miembros del Consejo proponiendo procedimientos, cada uno de los cuales, para el que lo proponía, era el procedimiento, el único que debía adoptarse» (1945: pp. 26-27). Pero es evidente que muchas de las medidas propuestas, lejos de ser excluyentes entre sí, podían resultar complementarias. Con todo, el desenlace fue el peor posible: en vista del cariz irreconciliable de la discusión, no se adoptó ninguna medida.

Por otro lado, una buena ilustración de los paralogismos de falsa oposición de tipo (3), que descartan los casos co-determinantes en atención al caso que se considera única o verdaderamente decisivo, sería la discusión que VAZ recoge y esquematiza en torno al problema del origen de las nacionalidades: «¿Qué es lo que hace verdaderamente una nacionalidad? —La raza, nos dice una escuela. —No, dice otra: las condiciones geográficas y geológicas. - Tampoco es cierto, dice una tercera: lo que hace las nacionalidades es la comunidad de religión. - Falso, dice una cuarta: lo que hace las nacionalidades es la comunidad de leyes. Y para otra será la comunidad de idioma, etc.» (1945:

9 Por lo demás, la posibilidad —después reconocida (28 B 851 y ss.) — del parecer de los bicéfalos o aturdidos sobre lo que es y no es, se refiere a otro género de fenómenos, el cosmológico, y pertenece a otro dominio cognitivo y expresivo, el de las opiniones de los mortales. Es obvio que este reconocimiento, en vez de corregir o atenuar la contraposición de partida, se suma a ella y viene a suplementarla en este otro dominio. 
pp. 40-41). Ahora bien, observa VAZ, la nacionalidad es «un algo» complejo y vago en cuya formación y explicación entran todos esos factores, aunque en proporciones distintas no sólo en general sino según los casos; así pues, quien sólo reconozca un factor y rechace la contribución o cooperación de los demás, «se condena fatalmente a pensar mal» (1945: p. 41).

La perspectiva analítica de VAZ sobre los paralogismos de falsa oposición tiene además otras dos peculiaridades importantes. Una estriba en la consideración de las relaciones mutuas o las posibles contaminaciones, digamos, entre diversos tipos de paralogismos, consideración que casa con la intención de tratar con disposiciones, usos o estados falaces concretos, antes que con clases generales o patrones abstractos de falacias. La otra peculiaridad consiste, en la atención prestada a sus proyecciones o secuelas tanto teóricas como prácticas, es decir: tanto en relación con las cuestiones planteadas o tratadas en el plano del pensamiento y del discurso, como en relación con los problemas a resolver o los asuntos a decidir en el terreno de la acción.

\section{RECAPITULANDO: UN PERFIL DEL PARALOGISMO}

Los paralogismos responden básicamente a este perfil: a) Dada su dinámica y concreta condición psico-lógica (i. e. psíquica y lógica), son procesos, estados o disposiciones normalmente detectables y evaluables por sus síntomas, efectos o secuelas, al menos en la medida en que pueden darse en un nivel pre- o sub-discursivo y pueden hacerse sentir antes que amoldarse a nuestros esquemas verbales y patrones lógicos. b) Conforman o inducen a confusiones, sesgos o distorsiones en las que se incurre con facilidad, y con menor, mayor y a menudo total inadvertencia. Se hallan muy extendidos y son difíciles de corregir, aunque algunos puedan parecer pueriles tras ser detectados. c) Desde un punto de vista lógico y cognitivo, constituyen no sólo errores sino fuentes de error con serias repercusiones tanto en el orden del pensamiento, como en el terreno de la acción — donde pueden conducir incluso a la inactividad-. En esta perspectiva, no representan fallos o errores esporádicos, sino más bien tendencias constitutivas de vicios.

Llegados a este punto, conviene recordar que los efectos o las secuelas de las disposiciones o procedimientos matrices también pueden ser, al menos en principio, no sólo negativos sino positivos. Cierto es que, en el balance final, prevalecen y son más graves los negativos, y por ello requieren mayor atención y un tratamiento especial. Pero VAZ no deja de reconocer ese doble signo de las fuentes de paralogismos y su doble proyección en usos legítimos e ilegítimos, estimulantes y perversos. El caso mismo de la oposición - del papel que los pares de contrarios desempeñan a veces como guía estructural de visiones del mundo y conceptualizaciones—, sería un buen ejemplo. De estas complejas condiciones de diagnóstico y evaluación se desprende que los juicios sobre los paralogismos han de ser respetuosos con su constitución indistinta y gradual por lo regular, y los dictámenes han de ser en correspondencia sutiles y ponderados. Más aún, al tratarse de cuestiones de grados y modulaciones que se dejan sentir antes que declarar, VAZ también creerá oportuno remitir su estimación y resolución a una suerte de instinto lógico o empírico (1945: pp. 192-194), o de buen sentido hiperlógico (1945: pp. 139, 192, 199), es decir, a una disposición o un hábito de sensibilidad, susceptible 
de formación y refuerzo, que deberá acompañar al examen lógico y al ejercicio del razonamiento en todas las cuestiones de ese género ${ }^{10}$.

\section{IDEAS PARA TENER EN CUENTA}

Pues bien, traslademos las ideas de VAZ desde su lugar psico-lógico de origen hasta el campo actual de la argumentación para considerar sus posibles sugerencias en este terreno.

\section{1}

Para empezar, propician una visión de la argumentación como una suerte de iceberg discursivo, cuya parte oculta o «sub-discursiva» es mucho mayor que la porción visible, el argumento explícito. Es una imagen ya establecida, pero que hoy nos conduce a la pragmática de las relaciones entre lo implícito y lo explícito antes que a la psicología supuestamente pre-lingüística o sub-lingüística de la Lógica viva. El trasfondo marino del iceberg de la argumentación no son precisamente las corrientes de la vida mental, sino más bien el tejido lingüístico de la comunicación y la conversación entre los agentes discursivos - donde el diálogo o la deliberación de uno consigo mismo, lejos de ser el caso paradigmático, es un caso derivado y límite-. Además, el reconocimiento y el control de unas disposiciones pre-discursivas como las supuestas se vuelven muy problemáticos en la medida en que tales disposiciones tengan que detectarse por introspección: la introspección no será un recurso muy efectivo para advertir los paralogismos debidos a inadvertencia o incompetencia. Más aún, para soslayar los sesgos del que emplea sofismas y las limitaciones del que cae en paralogismos, puede darse el caso de requerir el juicio de un tercero, mediación que presupone su expresión o trasunto lingüístico. Así pues, el traslado de las ideas de VAZ a nuestro tiempo comporta situar el paralogismo o las falacias en general en un nuevo marco: no consistirán ya en una disposición o un estado del espíritu, o en un modo de pensar — y menos aún de psiquear-, sino en actividades discursivas que tienen lugar en un contexto y con un propósito argumentativos (para dar cuenta y razón de algo a alguien, o para inducirle a creer o hacer determinadas cosas, por ejemplo). Todo lo cual supone, en fin, contar no sólo con las dimensiones «multiagenciales» — si se me permite la expresión a partir del neologismo «multiagentes»—e interactivas del discurso argumentativo, sino con las perspectivas pertinentes para su visión y reconocimiento, e.g. la dialéctica o la retórica, más allá de los aspectos lógicos y psicológicos en los que se detiene VAZ FERREIRA ${ }^{11}$. Aunque, para no incurrir en falsa opo-

${ }_{10}$ Así, por ejemplo: «Cuando hemos visto y pesado por el raciocinio las razones en pro y las razones en contra que hay en casi todos los casos, cuando hemos hecho toda la lógica (la buena lógica) posible, cuando las cuestiones se vuelve de grados, llega un momento en que una especie de instinto - lo que yo llamo el buen instinto hiper-lógico - es el que resuelve los casos concretos. Y sería bueno que la lógica no privara a los hombres de esta forma superior de buen sentido» (1945: p. 139). Se trataría de «una especie de instinto que sale de la experiencias general, que es como un resumen y concentración de la experiencia y que nos indica más o menos, que nos hace sentir aproximadamente cuál debe ser aquel grado más justo» (p. 193).

${ }_{11}$ Es sintomático que en las ocasiones en que advierte la incidencia de las maneras de presentar opiniones, planteamientos, ejemplos o argumentos, solamente se refiera a sus efectos psicológicos por contraste con 
sición, esta perspectiva discursiva no implique la exclusión o la falta de pertinencia de cualquier referencia psicológica en el ámbito de la teoría de la argumentación y, menos aún, en el terreno del pensamiento crítico. De hecho, hoy en día ha renacido una suerte de ave fénix neo-psicologista bajo el nombre de «protológica» y la forma de una teoría cognitiva que postula la existencia de un módulo de competencia lógica pre- o sublingüística, garante de nuestra normatividad y racionalidad discursiva (vid. HANNA,2006).

\section{2}

Demos un paso más. Hoy en día, las referencias de VAZ a los paralogismos como errores o fuentes de error en el sentido de usos o disposiciones concretas, frente a la idea tradicional de unas clases o patrones generales de falacias, suscitan un punto delicado. Sea C un contexto discursivo dado: ¿cabe distinguir entre el empleo falaz de un argumento en $\mathrm{C}$ y el empleo de un argumento falaz en C? Una consecuencia de la distinción sería admitir, en el primer caso, la posibilidad de un uso falaz o paralogístico de un buen argumento, posibilidad no contemplada por quien se atenga únicamente al segundo caso. VAZ, a tenor de sus observaciones críticas al planteamiento de las falacias de confusión por parte de S. MiLl y de su insistencia en los modos concretos de incurrir en usos o estados paralogísticos, apoyaría no sólo esta distinción, sino la prioridad del primer caso sobre el segundo. Una postura más radical, favorecida por la visión de la argumentación desde el punto de vista de la retórica, lleva a reducir el segundo caso al primero al sostener que los distintos usos de un mismo (patrón de) argumento conforman y determinan en realidad distintos argumentos en sus contextos de empleo. Pero, sin dar este paso reductor, también cabe reconocer la posibilidad de casos prácticamente indistinguibles o inciertos.

\section{3}

Sigamos. ¿Cabría pensar en las clases o tipos reconocidos de falacias como si fueran cristalizaciones de prácticas discursivas relativamente comunes y arraigadas, antes de pasar a su registro escolar en los manuales? Esta sugerencia casaría perfectamente con algunos rasgos de los paralogismos vazferreirianos: su comisión fácil y frecuente, por lo regular inadvertida; su arraigo y la dificultad de erradicarlos; su naturalidad, en suma.

Creo que además la idea podría rendir importantes servicios al estudio teórico de la argumentación falaz. Dos, en especial. Por un lado, contribuiría a explicar el atractivo y la capacidad de confusión o el poder de engaño que normalmente se atribuye a este género de discurso. Por otro lado, abriría una interesante perspectiva analítica en el tema de las falacias. Los dos descansan en un mismo supuesto básico: la consideración de los paralogismos como casos de mal funcionamiento de unas habilidades discursivas en las que solemos confiar. Un mal funcionamiento que, a la luz de la distinción tradicional de un principio entre paralogismos y sofismas, puede ser más bien endógeno y «espontá-

los lógicos, sin considerar su condición discursiva retórica — quizás bajo el influjo de una vieja idea de la oratoria-; cfr., por ejemplo, 1945: pp. 94-95; 145-149, 176-177, 201. 
neo», como el producido por el propio discurrir monológico de un agente, o más bien exógeno e inducido como el producido en un agente receptor por el éxito de una estrategia sofística de otro agente emisor del discurso. Pero un mal funcionamiento que, en todo caso, no es un fallo ocasional, sino que representa una tendencia con una inflexión o una inversión de signo: un modo de proceder que en ciertos contextos y con ciertos usos podría tener ciertas virtudes estimulantes, en otros ámbitos de aplicación y con otros usos pasa a constituir un vicio. Según esto, los paralogismos o las falacias en general, lejos de reducirse a meras disfunciones, constituyen confusiones habituales y errores de cierta trascendencia, amén de ser censurables como prácticas incorrectas; son vicios que piden corrección. Detengámonos un momento en este punto.

Si la idea de virtud, bajo la invocación de unas virtudes intelectuales, se encuentra hoy bien presente en epistemología, también podemos hallar en teoría de la argumentación, concretamente en el estudio de las falacias, una idea vagamente correlativa de vicio discursivo aunque no se llame así y se considere en una perspectiva más cognitiva que discursiva: según FogELIN y DuGGAN, «bajo la denominación de "falacia" criticamos cualquier procedimiento para fijar creencias que tenga una propensión inaceptablemente alta a generar creencias falsas o infundadas en relación con tal procedimiento» (1987: p. 257). Pues bien, en este mismo sentido externo —es decir al margen de las disposiciones y circunstancias concurrentes en el argumentador-, cabría trasladar el lenguaje «fiabilista» de las virtudes y los vicios al campo de la argumentación. Aquí vendría a ser virtuoso un proceso o procedimiento discursivo que, sin ser infalible, conduce normalmente y en un marco adecuado de empleo a la adopción de creencias o resoluciones fundadas y razonables. Sería un procedimiento de argumentación fiable en la medida en que, aplicado del modo apropiado en las condiciones debidas, produce por lo regular más creencias o decisiones justificadas o acertadas que injustificadas o erróneas. Paralelamente, se entendería por vicioso o viciado en este contexto un procedimiento discursivo que, sin necesidad de ser deliberadamente perverso, conduce normalmente a la adopción o al mantenimiento de creencias injustificadas, o de actitudes infundadas o de resoluciones no razonables, según sea el asunto en cuestión. Tal sería el caso general de los paralogismos, mientras que algunos sofismas o estrategias falaces, en particular, supondrían un modo de proceder deliberadamente inductor, perverso y engañoso, de modo que por esta puerta se nos volverían a colar las relaciones de interacción y los agentes discursivos. Pero en todo caso será un proceso o un proceder vicioso el que determine el carácter viciado del producto, antes que a la inversa, como parecían indicar los antiguos censos de formas de falacias ${ }^{12}$. Ahora bien, el punto crítico no radica simplemente en si estos modos falaces de proceder violan alguna pauta, regla o condición del buen argumentar o del argüir como es debido, según cabe suponer desde una obstinada tradición escolar en torno a las falacias - pues aun concediendo que toda práctica falaz sea una mala práctica argumentativa, de ahí no se sigue que toda mala argumentación sea una falacia-. El punto más bien estriba en que esos procedimientos viciosos o viciados dan al traste con la calidad de la argumentación o de la confrontación, sesgan la interacción y obstruyen o deterioran su curso y su desenlace,

\footnotetext{
${ }^{12}$ Otras importaciones de la ética y de la epistemología de la virtud dejan al margen la vertiente fiabilista y destacan otros aspectos de la concepción tradicional de la virtud, como la atención preferente al agente argumentador antes que a sus obras. Cfr., por ejemplo, ABERDEIN, 2006, y COHEN, 2007.
} 
en el marco discursivo dado. Lo que está en juego, en última instancia, es la calidad y la conformación de nuestro discurso público. Y a este respecto las prácticas falaces en su contexto reclaman una vez más su entidad propia y prioritaria frente a la reglamentación o la estandarización de las falacias.

\section{4}

Recordemos, en fin, otro rasgo distintivo del tratamiento vazferreiriano de los paralogismos para aprovechar la que aquí habrá de ser una última idea a tomar en cuenta. Se trata del cuidado y la lucidez de VAZ a la hora de ponderar tanto algunas virtudes como los claros vicios que pueden anidar en las actitudes determinantes de paralogismos: así, no olvida el valor y el poder estimulante de la contraposición, la precisión o el pensar por sistemas, al menos bajo ciertas formas y en ciertos contextos, aunque luego se echen a perder y sus perniciosas secuelas arrojen un saldo negativo. VAZ, en esta línea, da a entender que sus usos viciosos o viciados provienen de alguna suerte de extrapolación, arrogancia o exceso que convierte un procedimiento prometedor en un sesgo ruinoso. $Y$ esto puede ocurrir, por cierto, tanto con las buenas ideas como con las buenas observaciones ${ }^{13}$. La cuestión que entonces podría sugerir el discernimiento mostrado por VAZ en punto a las virtudes y vicios de los modos de proceder que dan en paralogismos, vendría a ser ésta: cómo es que ciertos procedimientos habituales posiblemente fiables y estimulantes, virtuosos, degeneran o se vician en ese mismo sentido discursivo y cognitivo.

No faltan en el entorno actual del estudio de las falacias indicaciones que pueden ayudarnos a situar esta cuestión en un marco teórico más básico y comprensivo. Nuestras habilidades como agentes discursivos forman parte de nuestras habilidades racionales como agentes, necesarias para nuestra supervivencia y nuestra calidad humana de vida. Estas habilidades tienen dos dimensiones o ámbitos de desempeño relevantes en el presente contexto: una cognitiva, relacionada con la información y su tratamiento, que viene a corresponder a la racionalidad teórica; otra estratégica, relacionada con el éxito de planes o proyectos y, en general, con nuestras actuaciones e interacciones con el entorno, que viene a corresponder a la racionalidad prudencial o práctica. Como agentes discursivos en una y otra dimensión, contamos con ciertos recursos, en especial información, tiempo y capacidad de procesamiento, de los que disponemos en un grado mayor o menor, aunque siempre limitado. Por ejemplo, si se trata de acometer y llevar a buen término empresas científicas o tecnológicas de cierta envergadura, una comunidad o una institución establecida dispondrá de esos recursos en mayor grado que uno cualquiera de sus individuos. Pero en todo caso, siempre dispondremos de ellos en grado limitado y habremos de actuar con información incompleta, falta de tiempo y di-

${ }_{13}$ Así, en la doctrina sistemáticamente naturista, «una idea excelente, como es la de seguir hasta cierto punto, hasta cierto grado, según los casos, las indicaciones naturales, ha sido echada a perder, y, en vez de ser ella un instrumento de verdad, se nos ha convertido en un instrumento de error; nos ha servido, por ejemplo, para destruir o para inhibir la acción de otras muchas verdades» (1945: p. 121). O a propósito de una posición higienista que llevara a sostener una teoría de la vacuna permanente por infección continua con microbios, «(U)na observación buena, excelente para haber hecho de ella un uso moderado y razonable, la hemos echado a perder y la hemos convertido en una causa de error, y de error funesto» (1945: p. 122). 
ficultades de procesamiento - como las experimentadas, en el terreno específicamente discursivo, con condicionales, negaciones y cuantificaciones incrustadas, modalidades iteradas, probabilidades compuestas, etc.-. Así que nos veremos abocados, en el marco de una economía de recursos precarios, a situaciones de riesgo donde habremos de confiar en ciertas habilidades comprobadas en la ejecución de tareas, aunque nunca tengamos, por lo regular, el éxito asegurado. Confiaremos, por ejemplo, en polarizaciones y oposiciones para introducir cierto orden en la conceptualización del mundo o para aprovecharnos de la eficacia y la economía discursivas de pautas de argumentación como «el silogismo disyuntivo», aunque a veces nos confundan las falsas contraposiciones o se nos vaya la mano en categorizaciones de falsos opuestos, extrapolaciones y, como VAZ diría, «trascendentalizaciones» erróneas. O, por poner otro caso, seguiremos confiando en nuestra inveterada tendencia a generalizar, e.g. a efectos de identificación, previsión o prevención, aunque esto no deje de llevarnos a veces a generalizaciones precipitadas o indebidas ${ }^{14}$. Confiaremos incluso aunque las cosas se compliquen al movernos entre diversos contextos discursivos o cuando, por ejemplo, entremos en conflicto entre lo que no es razonable desde un punto de vista, pongamos el teórico o cognitivo, pero parece razonable desde otro, pongamos el punto de vista práctico o estratégico ${ }^{15}$. En esta perspectiva del fallo de funcionamiento o de una mala ejecución de nuestras habilidades discursivas, se explica fácilmente la naturalidad con que podemos caer en paralogismos, la dificultad de corregirlos e incluso la peculiaridad de que a veces, aun siendo casos de mal proceder discursivo, nos parezcan buenos: se trataría de una situación parecida a la de los procedimientos o los mecanismos familiares que se nos descomponen o, en nuestra torpeza, descomponemos, de modo que, en palabras de VAZ, echamos a perder una idea excelente y lo que podría haber sido instrumento de la verdad se convierte en instrumento del error (1945: p. 121). El problema es que, por lo regular y salvo en dominios restringidos de aplicación de algoritmos elementales y métodos efectivos, no disponemos ni de criterios a priori de prevención de deslices o descuidos, ni de pautas capaces de garantizar el éxito. Luego, hemos de aprender de nuestros errores, así como de nuestros aciertos. O, mejor dicho, hemos de aprender de nuestros errores en el marco de nuestros aciertos, porque de lo contrario puede que no sobreviviéramos el tiempo suficiente para seguir aprendiendo.

\section{CODA}

Hasta aquí, en la estela de la Lógica viva de VAz FERREIRA, nos hemos ocupado de los paralogismos y, más en especial, de los paralogismos autoinducidos, aquellos en los

${ }^{14} \mathrm{~J}$. WoODs ha insistido en este caso y en el de la estimación de probabilidades conjuntas. También propone reinterpretar las falacias tradicionales en este marco del funcionamiento precario y la actuación fallida de nuestras habilidades en la ejecución de tareas cognitivas (WoODs, 2004: pp. 8-15 y 351 y ss.).

${ }^{15}$ Por ejemplo, investigaciones experimentales sobre el aprendizaje han mostrado que las ratas, tras una mala experiencia con ciertos alimentos en determinadas circunstancias, los descartan en cualquier otra circunstancia: es una medida drástica que seguramente les depara más creencias falsas que verdaderas, pero puede contribuir a mejorar sus probabilidades de preservación y supervivencia (véase STICH, 1985). En un sentido análogo cabe apreciar la prudencia preventiva de la paloma que empolla sus huevos en Alicia en el país de las maravillas (cap. 5), cuando recela de la niña que ha caído del cielo culebreando, tiene el cuello largo y reconoce haber comido huevos, al tomarla erróneamente por una serpiente. 
que el propio agente da en caer por confusión o por arrogancia o por inadvertencia. Pues bien, clas consideraciones y sugerencias avanzadas a este propósito pueden aplicarse no sólo al resto de los paralogismos cometidos de buena fe, sino extenderse hasta el otro extremo de los sofismas y generalizarse a toda suerte de falacias? Recordemos, sin ir más lejos, el último punto: cabe pensar que las disposiciones, condiciones o estados de confusión o inadvertencia que suelen propiciar los paralogismos típicos les hacen casi invulnerables o insensibles a las políticas sistemáticas de prevención o de erradicación. ¿Tendremos mejores expectativas de prevención y defensa cuando nos enfrentamos a tramas discursivas deliberadamente engañosas, a estrategias netamente sofísticas, a argucias expresas? A la luz de la situación dada en otros campos vecinos o afines — vista, pongamos por caso, la necesidad de servirse del «razonamiento por defecto» en múltiples contextos de acción e interacción discursiva, o de dejarse guiar por «heurísticos» en teoría de la decisión o, más en general, por presunciones y reglas heurísticas en diversos ámbitos del conocimiento común o científico-, considerando por añadidura la ausencia de una teoría cabal de las falacias y de criterios efectivos a priori de detección y prevención, no parece razonable esperar, al menos por ahora, medidas preventivas que nos libren definitivamente de toda suerte de deslices o nos garanticen el éxito en medio de las constantes experiencias de precariedad discursiva y cognitiva. Ni siquiera hay garantías de prever el momento en que, por decirlo en los términos pragma-dialécticos de F. VAN EEMEREN y P. HOUTLOSSER, nuestros ajustes estratégicos en el curso de una discusión «derrapan» y empiezan a deslizarse por la rampa de las falacias ${ }^{16}$. Tendremos que seguir aprendiendo. Por ejemplo, las ideas de VAZ sobre ciertas matrices de paralogismos, como la oposición excluyente o el pensar por sistemas, nos pueden poner en guardia ante posibles errores en este punto: de lo anterior, no se sigue que las confusiones e inadvertencias paralogísticas se extiendan por sistema como una maldición por todo el campo de las falacias, ni de la inexistencia de criterios de éxito a priori se desprende la exclusión de toda posible pauta de detección y toda posible medida preventiva. En su reciente revisión general de las falacias, Ch. TINDALE empieza asegurando que «los modos de evitar el razonamiento falaz, sea el debido a nosotros o sea el dirigido a nosotros, se reducen en su mayoría a algún tipo de educación» pues nacen, como ya apuntaba ARISTÓTELES, de la inexperiencia (TINDALE, 2007: p. 16). Al margen del juicio que nos pueda merecer esta pedagogía — es claramente insuficiente, por ejemplo, dentro de los marcos socio-institucionales de la argumentación que conforman los espacios o las «esferas» públicas del discurso ${ }^{17}$-, lo cierto es que la Lógica viva de VAZ FERREIRA sí puede ser, en efecto, sumamente ilustrativa y educativa.

El estudio de las falacias, como por lo demás el de otros muchos casos, procesos o estados discursivos y cognitivos, es hijo, diría Platón, de Poros, la abundancia, y de Penía, la penuria, una pareja de opuestos que no viven en falsa oposición. No disponemos de una definición cabal, ni de una teoría integradora de la argumentación falaz; peor aún, tampoco disponemos, ni seguramente podremos disponer, de una clasifica-

16 Véase VAN EEMEREN y HouTLOSSER, 2004: pp. 58-59 en especial.

17 En estos marcos, ciertas condiciones concurrentes como la opacidad, la asimetría o no-reciprocidad o la heteronomía de la interacción, pueden determinar bloqueos, sesgos y distorsiones del discurso público, cuya neutralización exigiría acciones o medidas preventivas de carácter socio-ético y socio-político que, por lo regular, se encuentran fuera del alcance, de la competencia o de la «educación» de cada uno de los individuos afectados. 
ción fina y exhaustiva de los gérmenes paralogísticos o de los especímenes sofísticos, ni de un tratamiento preciso y efectivo de detección y prevención de sus infecciones. Pero por otro lado, como ya mostraban los análisis y sugerencias de VAZ FERREIRA en la primera mitad del pasado siglo y en un medio lingüístico y cultural hispano, tenemos a nuestra disposición unas cuantas ideas dignas de recordarse y de tomarse en cuenta al respecto. Dada la situación, no estará de más desarrollarlas.

\section{REFERENCIAS BIBLIOGRÁFÍCAS}

Aberdein, A., 2006: «Virtue Argumentation», en Procds. 6th Conference of the ISSA, Amsterdam: Sic Sat, pp. 15-20.

Cohen, D. H., 2007: «Virtue Epistemology and Argumentation Theory», en Procds. Conference 2007 of the OSSA, CD-Rom, Windsor (Ontario): University of Windsor.

Damer, T. E., 2005: Attacking Faulty Reasoning, Belmont (CA): Thomson Wadsworth, 5. ${ }^{\text {e ed. }}$

Doury, M., y MoIrand, D. (eds.), 2004: L'Argumentation aujourd'bui, Paris: Presses Sorbonne Nouvelle (hay traducción en prensa, Barcelona: Montesinos, 2008)

EEMEREN, F. H. van, y Houtlosser, P., 2004: «Une vue synoptique de l'approche pragma-dialectique», en DOURY y MOIRAND (eds.), pp. 45-75.

Fogelin, R. J., y Duggan, T. J., 1987: «Fallacies», Argumentation, n. ${ }^{\circ}$ 1, pp. 255-262.

Hanna, R., 2006: Rationality and Logic, Cambridge (MA): The MIT Press.

Johnson-Laird, P. N., y SAVARY, F., 1999: «Illusory Inferences: a Novel Class of Erroneous Deductions», Cognition, 71, pp. 191-229.

MiLl, J. S., 1917: Sistema de Lógica inductiva y deductiva, Madrid: Daniel Jorro (trad. de E. OvEJERO Y MAURI a partir de la $6 .^{a}$ ed. inglesa; la 1 . $^{\text {a }}$ ed. data de 1843 ).

Palladino, J., 1962: «La Lógica Viva y la teoría de los sofismas», Revista de la Facultad de Humanidades y Ciencias, Montevideo, n. ${ }^{\circ}$ 3, pp. 165-192.

PoHL, R. F., 2004: Cognitive Illusions. A Handbook on Fallacies and Biases in Thinking, Judgement and Memory, Hove (UK)/New York: Psychology Press.

Stich, S. P., 1985: «Could Man Be an Irrational Animal? Some Notes on the Epistemology of Rationality», Synthese, n. ${ }^{\circ}$ 64, pp. 115-135.

Tindale, C., 2007: Fallacies and Argument Appraisal, Cambridge: Cambridge University Press.

VAz Ferreira, C., 1945: Lógica viva, Buenos Aires: Losada, 4. ${ }^{a}$ ed. La 1. a ed. data de 1910. La última edición en vida del autor es la 5. , 1952.

- 1956: Algunas conferencias sobre temas científicos, artísticos y sociales, Buenos Aires: Losada.

- 1979: Lógica viva. Moral para intelectuales, Caracas: Biblioteca Ayacucho. Incluye «Un paralogismo de actualidad» (1908) y otros textos de Fermentario, amén de un prólogo de M. CLAPS y una amplia bio-cronología de S. VAZ FERREIRA. Por desgracia, también abunda en errores tipográficos.

Woods, J., 2004: The Death of Argument. Fallacies in Agent-based Reasoning, Dordrecht: Kluwer. 